University of Nebraska - Lincoln

DigitalCommons@University of Nebraska - Lincoln

Immobilization of a Catalytic DNA Molecular Beacon on Au for $\mathrm{Pb}$ (II) Detection

\author{
Carla B. Swearingen \\ Daryl P. Wernette \\ Donald M. Cropek \\ Yi Lu \\ Jonathan V. Sweedler \\ See next page for additional authors
}

Follow this and additional works at: https://digitalcommons.unl.edu/usarmyresearch

Part of the Operations Research, Systems Engineering and Industrial Engineering Commons

Swearingen, Carla B.; Wernette, Daryl P.; Cropek, Donald M.; Lu, Yi; Sweedler, Jonathan V.; and Bohn, Paul W., "Immobilization of a Catalytic DNA Molecular Beacon on Au for Pb(II) Detection" (2005). US Army Research. 11.

https://digitalcommons.unl.edu/usarmyresearch/11

This Article is brought to you for free and open access by the U.S. Department of Defense at DigitalCommons@University of Nebraska - Lincoln. It has been accepted for inclusion in US Army Research by an authorized administrator of DigitalCommons@University of Nebraska - Lincoln. 


\section{Authors}

Carla B. Swearingen, Daryl P. Wernette, Donald M. Cropek, Yi Lu, Jonathan V. Sweedler, and Paul W. Bohn 


\title{
Immobilization of a Catalytic DNA Molecular Beacon on Au for Pb(II) Detection
}

\author{
Carla B. Swearingen, ${ }^{\dagger}$ Daryl P. Wernette, ${ }^{\dagger}$ Donald M. Cropek, ${ }^{\ddagger}$ Yi Lu, ${ }^{\star, \dagger}$ Jonathan V. Sweedler, ${ }^{\star, \dagger}$ and \\ Paul W. Bohn*,t
}

Beckman Institute for Advanced Science and Technology and Department of Chemistry, University of Illinois at UrbanaChampaign, 405 North Mathews Avenue, Urbana, Illinois 61801, and Construction Engineering Research Lab,

Interstate Research Park, 2902 Newmark Drive, Champaign, Illinois 61822

$\mathrm{A} \mathrm{Pb(II)-specific} \mathrm{DNAzyme} \mathrm{fluorescent} \mathrm{sensor} \mathrm{has} \mathrm{been}$ modified with a thiol moiety in order to immobilize it on a Au surface. Self-assembly of the DNAzyme is accomplished by first adsorbing the single-thiolated enzyme strand (HS-17E-Dy) followed by adsorption of mercaptohexanol, which serves to displace any $\mathrm{Au}-\mathrm{N}$ interactions and ensure that DNA is bound only through the Sheadgroup. The preformed self-assembled monolayer is then hybridized with the complementary fluorophorecontaining substrate strand (17DS-Fl). Upon reaction with $\mathrm{Pb}(\mathrm{II})$, the substrate strand is cleaved, releasing a fluorescent fragment for detection. Fluorescence intensity may be correlated with original $\mathrm{Pb}$ (II) concentration, and a linear calibration was obtained over nearly four decades: $10 \mu \mathrm{M} \geq[\mathrm{Pb}(\mathrm{II})] \geq 1 \mathrm{nM}$. The immobilized DNAzyme is a robust system; it may be regenerated after cleavage, allowing multiple sensing cycles. In addition, drying of fully assembled DNAzyme before reaction with $\mathrm{Pb}$ (II) does not significantly affect analytical performance. These results demonstrate that, in comparison with solutionbased schemes, immobilization of the DNAzyme sensor onto a Au surface lowers the detection limit (from 10 to $1 \mathrm{nM}$ ), maintains activity and specificity, and allows sensor regeneration and long-term storage. Realization of $\mathrm{Pb}$ (II) detection through an immobilized DNAzyme is the first important step toward creation of a stand-alone, portable $\mathrm{Pb}$ (II) detection device such as those immobilizing DNAzyme recognition motifs in the nanofluidic pores of a microfluidic-nanofluidic hybrid multilayer device.

Lead has historically been, and remains today, a persistent contaminant in the environment. Environmentally available $\mathrm{Pb}$ may originate from lead-based paints, soil and dust generated from gasoline and industrial pursuits, and water from pipes with leadcontaining connectors or joints. ${ }^{1}$ Regulatory improvements have been made, with bans on $\mathrm{Pb}$ additives in paints and reduction of $\mathrm{Pb}\left(\mathrm{C}_{2} \mathrm{H}_{5}\right)_{4}$ levels in gasoline both occurring in the 1970 s. However, because $\mathrm{Pb}$ is not biodegradable, it is still present in the

* To whom correspondence should be addressed. E-mail: yi-lu@uiuc.edu; jsweedle@uiuc.edu; p-bohn@uiuc.edu.

$\dagger$ University of Illinois at Urbana-Champaign.

* Construction Engineering Research Lab.

(1) Centers for Disease Control (U.S.). Preventing lead poisoning in young children: a statement, [4th revision] ed.; The Centers: Atlanta, GA, 1991. environment today. Compounding the problem is the reality that lead use remains legal in many military and industrial settings.

Lead is particularly harmful to children because of their small size and developing bodies. Although known to affect every system, $\mathrm{Pb}$ has uniquely deleterious effects on the brain and central nervous system. At high blood levels $(>18 \mu \mathrm{M})$, coma and death can occur. ${ }^{1}$ While incidence of $\mathrm{Pb}$ poisoning at this level is rare, a worrisome percentage of school-aged children still have $\mathrm{Pb}$ levels in blood that are considered harmful. Indeed, the blood $\mathrm{Pb}$ level considered harmful has itself fallen dramatically over the past four decades. A level above $3 \mu \mathrm{M}$ was considered toxic in the 1960s. However, by the 1990s, blood concentrations as low as $500 \mathrm{nM}$ had been associated with decreased intelligence, behavioral problems, and impaired growth. ${ }^{1}$ Given the environmental availability of $\mathrm{Pb}$ and the dire consequences of accidental exposure, especially on the young, it is not surprising that a push is being made to develop sensitive and robust analytical approaches for sensing of $\mathrm{Pb}$ in the field.

The most commonly used detection techniques for laboratoryscale $\mathrm{Pb}$ determinations have been atomic absorption spectroscopy and ICP, due mainly to their high sensitivity for $\mathrm{Pb}$ and relative simplicity. ${ }^{2-6}$ Analytical advancements have provided a detection limit of $\sim 1 \mathrm{nM} .{ }^{7,8}$ Electrochemical methods have better sensitivity and correspondingly lower detection limits, though interference from a wide range of ions can compromise the selectivity. ${ }^{9-12}$ Colorimetric tests for $\mathrm{Pb}$ (II) based on sulfide or rhodizonate have been widely used for decades due to their portability and costeffectiveness. ${ }^{13,14}$ Nanoparticle-based sensors are also being developed for $\mathrm{Pb}$ detection providing additional colorimetric methods

(2) Ma, R.; Mol, W. V.; Adams, F. Anal. Chim. Acta 1994, 285, 33-43.

(3) Liu, J.; Chen, H.; Mao, X.; Jin, X. Int. J. Environ. Anal. Chem. 2000, 76, $267-282$.

(4) Ochsenkuhn-Petropoulou, M.; Ochsenkuhn, K. M. Fresenius' J. Anal. Chem. 2001, 369, 629-632.

(5) Elfering, H.; Andersson, J. T.; Poll, K. G. Analyst 1998, 123, 669-674.

(6) Fang, Z.; Sperling, M.; Welz, B. J. Anal. At. Spectrosc. 1991, 6, 301-306.

(7) Wuilloud, R. G.; Acevedo, H. A.; Vazquez, F. A.; Martinez, L. D. Anal. Lett. 2002, 35, 1649-1665.

(8) Di Nezio, M. S.; Palomeque, M. E.; Band, B. S. F. Talanta 2004, 63, 405409 .

(9) Crowley, K.; Cassidy, J. Electroanalysis 2002, 14, 1077-1082.

(10) Ganjali, M. R.; Rouhollahi, A.; Mardan, A. R.; Hamzeloo, M.; Mogimi, A.; Shamsipur, M. Microchem. J. 1998, 60, 122-133.

(11) Sokalski, T.; Ceresa, A.; Zwickl, T.; Pretsch, E. J. Am. Chem. Soc. 1997, 119, 11347-11348.

(12) Sussell, A.; Ashley, K. J. Environ. Monit. 2002, 4, 156-161. 
with detection limits of $\sim 100 \mathrm{nM} \cdot{ }^{15,16}$ New optical sensors have been developed and exhibit high sensitivity but are currently expensive to produce. ${ }^{17-20}$ It would be advantageous to develop a sensor that combines the desirable properties of these sensors, that is portable, and that is capable of detecting $\mathrm{Pb}$ with both high sensitivity and high selectivity at reasonable cost.

In vitro selection is a powerful technique that has been used to isolate deoxyribozymes (DNAzymes) that are cleaved by a variety of analytes, including metal ions. ${ }^{21-23}$ Specifically, a DNAzyme that is cleaved selectively by $\mathrm{Pb}$ (II) has been developed in our laboratories. ${ }^{24}$ Briefly, the in vitro selection process involves using a large random sequence pool of DNA ( $\sim 10^{14}$ sequences), with each sequence containing a single ribonucleic adenosine ( $\mathrm{rA}$ ) base. The random sequence pool of modified DNAzyme is immobilized on a column and then reacted with $\mathrm{Pb}$ (II)-containing eluent. The DNAzyme is cleaved upon exposure to $\mathrm{Pb}$ (II) at the rA base, because rA is susceptible to hydrolytic cleavage. The fragmented DNAzyme is eluted after cleavage in quantities determined by the efficiency of the $\mathrm{Pb}$ (II)-induced cleavage reaction for each specific sequence. The most abundant fragments are amplified with PCR, reconstructed to contain rA, and the corresponding sequences are reapplied to the column, followed by another exposure to $\mathrm{Pb}(\mathrm{II})$, but under more stringent conditions. Specificity can be further increased by incorporating a negative selection criterion in which DNAzymes that are reactive with analytes other than $\mathrm{Pb}$ (II) are eliminated, until only a small number of reactive sequences remain. ${ }^{25}$ The process is repeated many times, until the single sequence that is most efficient and selective for recognizing $\mathrm{Pb}$ (II) is identified. At this point, the DNAzymes are sequenced. This DNA sequence is strategically divided to create an enzyme strand that contains the random base sequence and a complementary substrate strand that contains the rA base and cleaves in the presence of $\mathrm{Pb}(\mathrm{II})$.

To create an effective sensor, detection of small amounts of the $\mathrm{DNAzyme}-\mathrm{Pb}$ (II) reaction product must be possible. To this end, a molecular beacon strategy is implemented by fluorescence labeling of the original $\mathrm{Pb}$ (II)-specific DNAzyme. ${ }^{26}$ In this case, the substrate strand (17DS) is labeled with a fluorophore at the $5^{\prime}$ end, while the enzyme strand (17E) is labeled with a corresponding quencher at the 3 ' end. When the strands are hybridized, fluorescence is effectively quenched, and little signal is observed. The principal background fluorescence arises due to incomplete

(13) Schmehl, R. L.; Cox, D. C.; Dewalt, F. G.; Haugen, M. M.; Koyak, R. A.; Schwemberger, J. G., Jr.; Scalera, J. V. Am. Ind. Hyg. Assoc. J. 1999, 60, 444-451.

(14) Ashley, K.; Hunter, M.; Tait, L. H.; Dozier, J.; Seaman, J. L.; Berry, P. F. Field Anal. Chem. Technol. 1998, 2, 39-50.

(15) Liu, J.; Lu, Y. J. Am. Chem. Soc. 2003, 125, 6642-6643.

(16) Liu, J. W.; Lu, Y. J. Fluoresc. 2004, 14, 343-354.

(17) Yusof, N. A.; Ahmad, M. Talanta 2002, 58, 459-466.

(18) Blake, D. A.; Blake, R. C., II; Khosraviani, M.; Pavlov, A. R. Anal. Chim. Acta 1998, 376, 13-19.

(19) Wilson, R.; Schiffrin, D. J.; Luff, B. J.; Wilkinson, J. S. Sens. Actuators, B 2000, B63, 115-121.

(20) Reese, C. E.; Asher, S. A. Anal. Chem. 2003, 75, 3915-3918.

(21) Breaker, R. R.; Joyce, G. F. Chem. Biol. 1994, 1, 223-229.

(22) Li, Y.; Breaker, R. R. Curr. Opin. Struct. Biol. 1999, 9, 315-323.

(23) Lu, Y. Chem. Eur. J. 2002, 8, 4588-4596.

(24) Li, J.; Zheng, W.; Kwon, A. H.; Lu, Y. Nucleic Acids Res. 2000, 28, 481488.

(25) Bruesehoff, P. J.; Li, J.; Augustine, I. A. J.; Lu, Y. Comb. Chem. High Throughput Screening 2002, 5, 327-335.

(26) Li, J.; Lu, Y. J. Am. Chem. Soc. 2000, 122, 10466-10467. hybridization. Upon reaction with $\mathrm{Pb}$ (II), the substrate strand is cleaved, releasing the fluorescent portion for detection. Solutionbased operation elicits a linear working curve in the range $4 \mu \mathrm{M}$ $\geq[\mathrm{Pb}(\mathrm{II})] \geq 10 \mathrm{nM}$, indicating a sensitivity that rivals that of atomic absorption. ${ }^{26}$ In addition, selectivity was greatly enhanced over other divalent metal ions with several thousandfold selectivity over $\mathrm{Mn}$ (II), $\mathrm{Ni}$ (II), Cd(II), $\mathrm{Cu}$ (II), $\mathrm{Mg}$ (II), and $\mathrm{Ca}$ (II) and $\sim 80$ fold selectivity over the next best competitor $\mathrm{Co}$ (II).

Until now, the $\mathrm{Pb}$ (II)-specific DNAzyme sensor has been limited to bulk solution reactions. There are two inherent advantages associated with moving to a surface-immobilized sensor. First, since hybridization of enzyme and substrate strands is never complete, background fluorescence is observed, even in the absence of a specific cleavage reaction. Because noise in the background fluorescence is a fundamental limitation when working at low analyte concentrations, efforts to reduce the background can produce lower limits of detection. Immobilization of DNAzymes on a surface can overcome limited hybridization efficiency, making it feasible to wash away unhybridized fluorescent substrate DNA, thus reducing the background fluorescence, a task not easily achievable when DNAzymes are in bulk solution. Second, the surface-immobilized DNAzyme may be regenerated and used multiple times, a possibility that is not straightforward in solutionbased sensors. Hybridization of surface-bound DNA has been shown to be reversible, suggesting the possibility of reusing the surface for successive measurements. ${ }^{27}$ For example, Ramachandran et al. produced a surface-immobilized DNA molecular beacon that exhibited $75 \%$ of the original signal intensity after one regeneration..$^{28}$

Despite the above benefits, transforming DNAzyme sensors from bulk solution to planar surfaces is not trivial, because surface interactions may interfere with the DNAzymes' activity. Therefore biotin-avidin has been used for immobilization of DNAzyme on planar gold surfaces to prevent direct interaction between the DNAzyme and the gold surface. ${ }^{30}$ Detection methods used for hybridization and activity in this scheme are based on surface plasmon resonance. While DNAzyme does retain its activity using this method, it was desirable to find a simpler and less expensive way to immobilize the DNAzyme as well as a more sensitive method of detection, such as fluorescence.

Though many strategies for immobilization exist, exploiting $\mathrm{Au}$-thiol chemisorption is attractive due to ease of preparation and broad applicability. Thiol-gold chemistry for DNAzyme immobilization has been demonstrated for Au nanoparticle functionalization, $15,16,31,32$ but the different surface termination chemistry and the drastically different diffusion properties of planar surfaces mean that utilizing Au-thiol chemistry for immobilization of DNAzyme on planar surfaces is a nontrivial undertaking.

Organothiols readily self-assemble on Au surfaces, forming densely packed monolayers (SAMs) with the distal end of the

(27) Levicky, R.; Herne, T. M.; Tarlov, M. J.; Satija, S. K. J. Am. Chem. Soc. 1998 120, 9787-9792.

(28) Ramachandran, A.; Flinchbaugh, J.; Ayoubi, P.; Olah, G. A.; Malayer, J. R. Biosens. Bioelectron. 2004, 19, 727-736.

(29) Deleted in proof.

(30) Okumoto, Y.; Ohmichi, T.; Sugimoto, N. Biochemistry 2002, 41, 27692773.

(31) Ito, Y.; Hasuda, H. Biotechnol. Bioeng. 2004, 86, 72-77.

(32) Liu, J.; Lu, Y. Anal. Chem. 2004, 76, 1627-1632. 


\section{Table 1. DNA Labels and Sequences}
$17 \mathrm{E}$
17DS
5'-CATCTCTTCTCCGAGCCGGTCGAAATAGTGAGT-3'
HS-17E-Fl
HS-17E-Dy
5'-ACTCACTATrAGGAAGAGATG-3'
17DS-Fl

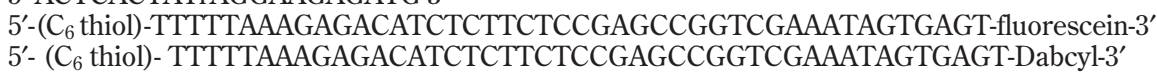 5'-fluorescein-ACTCACTATrAGGAAGAGATGTCTCTTT-3'

thiol solution-accessible. ${ }^{33-35}$ DNA can be tethered to $\mathrm{Au}$ in a straightforward manner by thiolating one end of the DNA. ${ }^{36-40}$ However, DNA does not typically form densely packed monolayers, the detailed packing structure of DNA SAMs depending on several factors, including, importantly, oligonucleotide length. Due to the propensity of Lewis bases, especially nitrogen-based moieties, to chemisorb to $\mathrm{Au}$, bases along the DNA backbone also interact with the surface. ${ }^{41}$ Tarlov and co-workers have developed a unique method to combat multivalent adsorption of thiolated DNA by mixing monolayers of DNA with mercaptohexanol (MCH). ${ }^{27,42,43}$ In this process, the DNA-modified substrate is soaked in $\mathrm{MCH}$ after formation of the DNA SAM, effectively displacing $\mathrm{N}-\mathrm{Au}$ bonds, leaving DNA bound only at the $\mathrm{S}$ headgroup. In addition, this increases the average distance between adjacent DNA molecules, producing an environment more conducive to physical access of complementary strands for hybridization. Mixed monolayers have also been shown to be stable through sensor regeneration, with no loss of specificity. ${ }^{42}$

In the present work, $\mathrm{MCH}-\mathrm{DNA}$ mixed monolayers are utilized to immobilize the DNAzyme on a Au surface with the goal of creating a surface-based $\mathrm{Pb}$ (II) sensor. Conditions for optimum surface immobilization and hybridization are defined, and the resulting structures are characterized with respect to their ability to detect $\mathrm{Pb}$ (II) sensitively and selectively. Sensor regeneration is also explored.

\section{EXPERIMENTAL SECTION}

Oligonucleotide Sequences. DNA enzyme strand, 17E, with modifications was purchased from Integrated DNA Technologies (IDT) or from Trilink Bio Technologies, Inc., while the DNA/ RNA chimeric substrate strand, 17DS, with modifications was purchased from IDT. All oligonucleotides and abbreviations are shown in Table 1. All reagents were purchased from Aldrich, Inc. and were used without additional purification, with the exception of buffer solutions, which were chelated for divalent metal ions using Chelex 100 beads.

(33) Porter, M. D.; Bright, T. B.; Allara, D. L.; Chidsey, C. E. D. J. Am. Chem. Soc. 1987, 109, 3559-3568.

(34) Nuzzo, R. G.; Allara, D. L. J. Am. Chem. Soc. 1983, 105, 4481-4483.

(35) Nuzzo, R. G.; Fusco, F. A.; Allara, D. L. J. Am. Chem. Soc. 1987, 109, 23582368.

(36) Kelley, S. O.; Barton, J. K.; Jackson, N. M.; McPherson, L. D.; Potter, A. B.; Spain, E. M.; Allen, M. J.; Hill, M. G. Langmuir 1998, 14, 6781-6784.

(37) Hegner, M.; Wagner, P.; Semenza, G. FEBS Lett. 1993, 336, 452-456.

(38) Du, H.; Disney, M. D.; Miller, B. L.; Krauss, T. D. J. Am. Chem. Soc. 2003, $125,4012-4013$.

(39) Nakamura, F.; Ito, E.; Sakao, Y.; Ueno, N.; Gatuna, I. N.; Ohuchi, F. S.; Hara, M. Nano Lett. 2003, 3, 1083-1086.

(40) Marie, R.; Jensenius, H.; Thaysen, J.; Christensen, C. B.; Boisen, A. Ultramicroscopy 2002, 91, 29-36.

(41) Petrovykh, D. Y.; Kimura-Suda, H.; Whitman, L. J.; Tarlov, M. J. J. Am. Chem. Soc. 2003, 125, 5219-5226.

(42) Herne, T. M.; Tarlov, M. J. J. Am. Chem. Soc. 1997, 119, 8916-8920.

(43) Steel, A. B.; Herne, T. M.; Tarlov, M. J. Anal. Chem. 1998, 70, 4670-4677.
Planar Au Surfaces. Planar Au surfaces were produced by vapor deposition onto glass microscope slides. Glass microscope slides were first cleaned in piranha solution $\left(70 \% \mathrm{H}_{2} \mathrm{SO}_{4}, 30 \% \mathrm{H}_{2} \mathrm{O}_{2}\right)$ for $30 \mathrm{~min}$ followed by thorough rinsing with deionized (18 $\mathrm{M} \Omega$ $\mathrm{cm}$ ) water. (CAUTION: Piranha is a vigorous oxidant and should be used with extreme caution!) After cleaning, the glass slides were rinsed with isopropyl alcohol and dried with a dry $\mathrm{N}_{2}$ stream. Prior to Au film deposition, $\mathrm{Cr}$ was deposited as an adhesion layer at a rate of $0.1 \AA / \mathrm{s}$ to a final thickness of $50 \AA$. Au was then deposited at a rate of $1 \AA$ /s to a final thickness of $500 \AA$. Freshly prepared $\mathrm{Au}$ films were stored in a dry $\mathrm{N}_{2}$ atmosphere until ready for use. Before use, Au surfaces were cleaned with piranha solution for $20 \mathrm{~min}$ and rinsed with deionized water for $5 \mathrm{~min}$.

Assembly of DNA SAMs on Au. Assembly of thiolated DNA on $\mathrm{Au}$ and hybridization of complementary DNA followed previously reported methods. ${ }^{27,42,44}$ Immobilization of HS-17E-Dy (or HS-17E-Fl) on Au was achieved by soaking piranha-cleaned $\mathrm{Au}$ surfaces $\left(\sim 0.5 \times 0.5 \mathrm{~cm}^{2}\right)$ in a solution composed of $1 \mathrm{M}$ potassium phosphate buffer ( $\mathrm{pH}=6.9), 100 \mu \mathrm{M}$ tris(2-chloroethyl) phosphate (TCEP), and $1 \mu \mathrm{M}$ HS-17E-Dy (or HS-17E-Fl) for 90 min. TCEP was added in order to reduce disulfide bonds or oxidized thiols that may have formed. ${ }^{44}$ Surfaces were then thoroughly rinsed in deionized water and immediately soaked in $1 \mathrm{mM}$ mercaptohexanol for $5 \mathrm{~min}$. Subsequently, surfaces were thoroughly rinsed in $50 \mathrm{mM}$ tris acetate buffer $(\mathrm{pH}=7.2)$ and 1 $\mathrm{M} \mathrm{NaCl}$. Hybridization was accomplished by soaking in $1 \mu \mathrm{M}$ 17DS-Fl in $50 \mathrm{mM}$ tris acetate buffer $(\mathrm{pH}=7.2)$ and $1 \mathrm{M} \mathrm{NaCl}$ in a $70{ }^{\circ} \mathrm{C}$ water bath for $60 \mathrm{~min}$. The bath was then allowed to cool to room temperature over $60 \mathrm{~min}$, cooled to $4^{\circ} \mathrm{C}$ for $30 \mathrm{~min}$, and again allowed to come to room temperature.

Detection of $\mathrm{Pb}(\mathrm{II})$ by DNAzyme in Solution. Solution assays of DNAzyme were performed with $10 \mathrm{nM}$ HS-17E-Dy and $10 \mathrm{nM}$ 17DS-Fl in $50 \mathrm{mM}$ tris acetate buffer $(\mathrm{pH}=7.2)$ and 50 $\mathrm{mM} \mathrm{NaCl}$. A $100 \mu \mathrm{M}$ solution of TCEP was also added. Hybridization was accomplished by heating in a $70{ }^{\circ} \mathrm{C}$ water bath for 60 min and cooling to room temperature over $60 \mathrm{~min}$. The solution was then cooled to $4{ }^{\circ} \mathrm{C}$ for $30 \mathrm{~min}$ and again allowed to come to room temperature. Fluorescence spectra was recorded using a 0.5 by $0.5 \mathrm{~cm}^{2}$ quartz cell in a Jobin Yvon Fluoromax-P fluorometer $\left(\lambda_{\mathrm{ex}}=491 \mathrm{~nm}\right.$ and $\left.\lambda_{\mathrm{em}}=500-575 \mathrm{~nm}\right)$. A $10 \mu \mathrm{M}$ solution of $\mathrm{Pb}$ (II) was then added, and after 5 min reaction time, fluorescence spectra again documented.

Detection of $\mathrm{Pb}(\mathrm{II})$ by Immobilized DNAzyme. Prior to using the substrate-immobilized DNAzyme for $\mathrm{Pb}$ sensing, it was soaked in $50 \mathrm{mM}$ tris acetate buffer $(\mathrm{pH}=7.2)$ and $50 \mathrm{mM} \mathrm{NaCl}$ solution for $5 \mathrm{~min}$ in an effort to remove any remaining physisorbed substrate strand, which was minimized by $\mathrm{MCH}$ passivation, and to rinse away any dissociated substrate strand at the lower $\mathrm{NaCl}$ concentration. Measurements were made by placing

(44) Aqua, T.; Naaman, R.; Daube, S. S. Langmuir 2003, 19, 10573-10580. 
the assembled DNAzyme-MCH SAM in a $\mathrm{Pb}$ (II)-containing solution in $50 \mathrm{mM}$ tris acetate buffer $(\mathrm{pH}=7.2)$ and $50 \mathrm{mM} \mathrm{NaCl}$. The DNAzyme surface was allowed to react with the $\mathrm{Pb}$ solution for $60 \mathrm{~min}$, after which it was removed and then rinsed with the reaction solution. Single-wavelength fluorescence intensity of the cleaved DNA portion in the solution was determined with $\lambda_{\mathrm{ex}}=$ $491 \mathrm{~nm}$ and $\lambda_{\mathrm{em}}=518 \mathrm{~nm}$. Since no fluorescence peak shift or shape change was observed under varying experimental conditions, the measurement of peak integrated areas and peak maximums produced similar values (within $5 \%$ ). Thus, fluorescence peak intensities have been used for simplicity and because they allow real-time monitoring and rapid measurements during kinetic experiments.

Regeneration of Active DNAzyme Substrates. For determination of regeneration, the surface-immobilized DNAzyme was first prepared as described above. After an initial reaction of the sensor with $\mathrm{Pb}$ (II), the activity was determined by fluorescence measurements. The reacted sensors were subsequently soaked, individually, in Millipore water for $18 \mathrm{~h}$ in closed sample vials. The samples were then rinsed with Millipore water for $5 \mathrm{~min}$. Hybridization of 17DS-Fl was repeated by soaking the reacted sensors in $50 \mathrm{mM}$ tris acetate buffer at $\mathrm{pH}=7.2$ and $1 \mathrm{M} \mathrm{NaCl}$ with $1 \mu \mathrm{M}$ 17DS-Fl with the same heating and cooling described above. Nonregenerated control samples were soaked in identical buffer solutions and heating conditions, without 17DS-Fl. The controls and regenerated substrates were reacted with $10 \mu \mathrm{M}$ $\mathrm{Pb}$ (II) in $50 \mathrm{mM}$ tris acetate buffer $(\mathrm{pH}=7.2)$ and $50 \mathrm{mM} \mathrm{NaCl}$ for $60 \mathrm{~min}$. The reaction solution was rinsed over the surface of the sensor and fluorescence intensity determined.

\section{RESULTS AND DISCUSSION}

Activity of DNAzyme in Solution. The DNAzyme used is slightly modified from that used in previous publications, ${ }^{26,45}$ and thus, its solution activity was first assessed. The enzyme strand has been modified by addition of a thiol group via a $\left(\mathrm{CH}_{2}\right)_{6}$ linker to a 5-T linker and extension of the arm nearest the thiol modification. The substrate strand has had its complementary arm extended to match that of the enzyme strand up to the poly $T$ linker.

While previously reported DNA array techniques employ a longer polyT linker (10-15 bases), a 5-T linker was chosen for two reasons. First, previous work has shown that $100 \%$ hybridization efficiency is achieved using this $\mathrm{MCH}$ backfilling methodology in the absence of any polyT linker; i.e., the $\left(\mathrm{CH}_{2}\right)_{6}$ chain between the thiol headgroup and the complementary portion of the nucleotide sequence is sufficient for extending the DNA above the $\mathrm{MCH}$ layer for complete hybridization. ${ }^{27,42}$ Second, singlemolecule fluorescence resonance energy-transfer work in our laboratories has shown that a 5-T linker is sufficient for DNAzyme activity (unpublished observation).

As seen in Figure 1, when 17DS-Fl is hybridized with HS-17EDy in solution, fluorescence intensity is relatively low. After addition of $10 \mu \mathrm{M} \mathrm{Pb}$ (II), fluorescence intensity increases by $270 \%$ after only 5 min reaction time at $300 \mathrm{~K}$, compared to a $60 \%$ increase observed for the previously reported sequence. ${ }^{46}$ The increased ratio is attributed to the extension of the tethering arm, thereby

(45) Liu, J. W.; Lu, Y. J. Am. Chem. Soc. 2003, 125, 6642-6643.

(46) Liu, J.; Lu, Y. Anal. Chem. 2003, 75, 6666-6672.

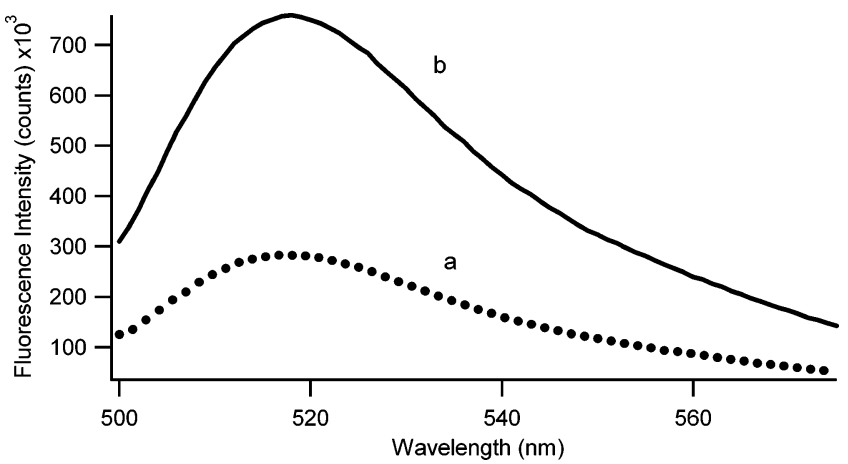

Figure 1. Fluorescence spectra for the (a) $10 \mathrm{nM}$ 17DS-FI +10 nM HS-17E-Dy and (b) after addition of $10 \mu \mathrm{M} \mathrm{Pb}(\mathrm{II})$.

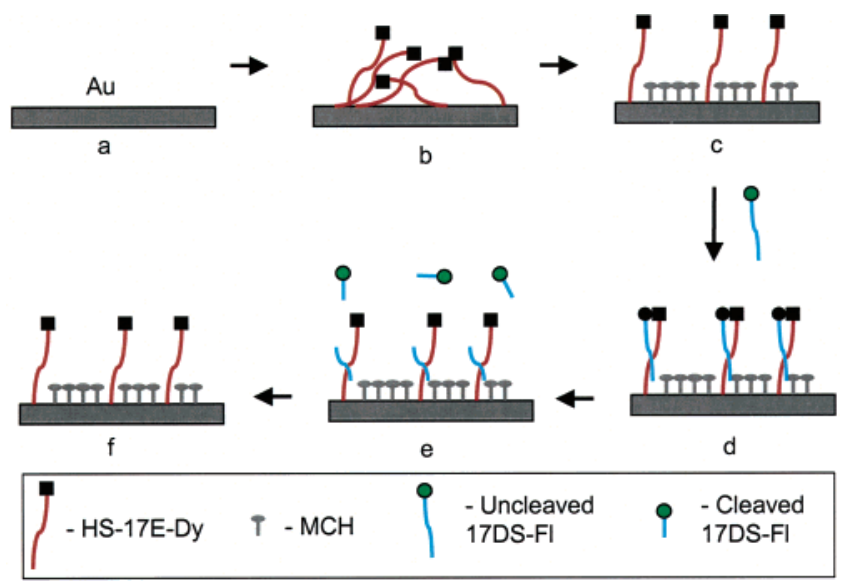

Figure 2. Schematic of the immobilization and $\mathrm{Pb}(\mathrm{II})$ reaction process. (a) piranha-cleaned Au surface, (b) assembly of HS-17EDy, (c) subsequent assembly of $\mathrm{MCH}$, (d) hybridization with 17DS$\mathrm{Fl}$, (e) reaction with $\mathrm{Pb}(\mathrm{II})$ cleaves 17DS-FI, and (f) water soak removes the 17DS-FI fragment remaining from cleavage, prior to regeneration.

increasing hybridization efficiency at room temperature. Spectra show no peak shift or shape change after cleavage. It is also inferred that the addition of a sulfhydryl headgroup and polyT linker has no discernible effect on $\mathrm{Pb}$-induced cleavage and generation of luminescence.

Activity of DNAzyme on Au Surfaces. Figure 2 illustrates the basic immobilization and reaction protocol used throughout this work. Thiolated enzyme strand is immobilized on Au via thiol chemisorption; the surface is back-filled with $\mathrm{MCH}$; and substrate strand is hybridized onto enzyme strand to prepare the DNAzyme surface for $\mathrm{Pb}$ detection. Upon reaction with $\mathrm{Pb}(\mathrm{II})$, the fluorophore-containing portion is released into solution, where it can subsequently be detected. The goal of this work is to establish the activity and figures of merit for the fluorogenic $\mathrm{Pb}$ (II)DNAzyme reaction, when the DNAzyme is initially immobilized on a planar Au substrate.

The choice of sampling time is important in this experiment. To determine the optimal time of reaction, a kinetic experiment was performed. The surface-immobilized DNAzyme was reacted with $10 \mu \mathrm{M} \mathrm{Pb}$ (II) in quiescent solution, and fluorescence intensities were collected at 10-min intervals. Figure 3 shows fluorescence intensity versus time for an active, Au-bound DNAzyme upon addition of $\mathrm{Pb}$ (II). The solid line shows a fit to a secondorder reaction with fluorescence intensity proportional to $t^{1 / 2}$, typical of a diffusion-limited process. A mechanism in which the 


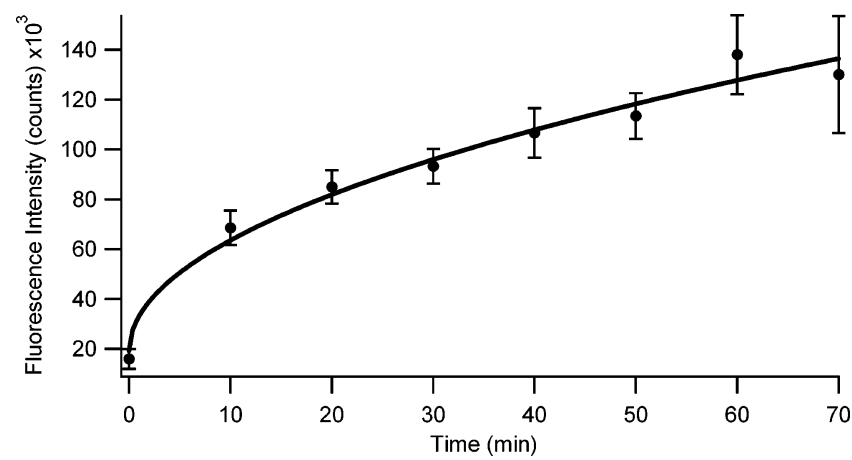

Figure 3. Fluorescence intensities for $\mathrm{Pb}(\mathrm{II})$ reaction doublestranded DNAzyme on Au surface as a function of time. The $10 \mu \mathrm{M}$ $\mathrm{Pb}$ (II) added at time $t=0$. Error bars represent the standard deviation obtained from replicate measurements on three distinct surfaces, and the solid line is a fit to $I(t)=I_{0}+k t^{1 / 2}$, with $I_{0}=15889$ and $k=$ $13288 \mathrm{~min}^{-1 / 2}$.

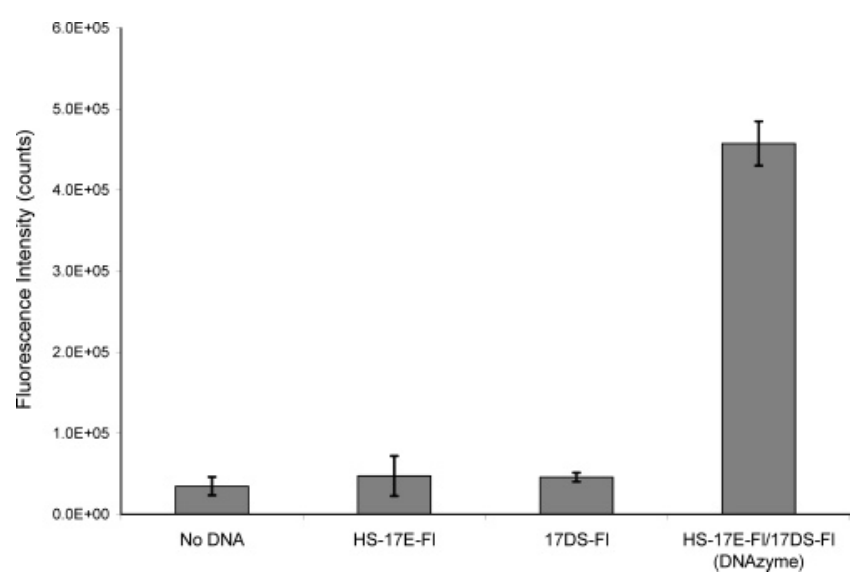

Figure 4. Fluorescence intensities produced by exposure of four surfaces to $10 \mu \mathrm{M} \mathrm{Pb}$ (II). Three negative controls, no DNA, HS-17E$\mathrm{FI}, 17 \mathrm{DS}-\mathrm{FI}$, and a positive control, DNAzyme. Error bars represent the standard deviation obtained from replicate measurements on at least two distinct surfaces.

rate-limiting step is diffusion of species to and away from the $\mathrm{Au}$ surface, rather than the reaction of DNAzyme with $\mathrm{Pb}(\mathrm{II})$, is consistent with the rapid DNAzyme cleavage observed in solution. Clearly the fluorescence intensity nears saturation at times $t>1$ $\mathrm{h}$, from which it was determined that $1 \mathrm{~h}$ is an appropriate reaction time for quantitative $\mathrm{Pb}$ (II) determinations.

A control experiment was carried out to ensure that the DNAzyme is actually immobilized, rather than simply physisorbed on the Au surface. For this experiment, both 17E and 17DS strands were labeled with fluorescein. With both strands labeled, if either DNA strand is removed from the surface in the absence of specific cleavage, it can be detected by fluorescence. Figure 4 shows the steady-state fluorescence intensity after addition of $\mathrm{Pb}$ (II) to a series of four $\mathrm{Au}$-DNA SAMs: DNAzyme and three negative controls consisting of no DNA, 17E only, and 17DS only. Clearly, fluorescence intensities are comparable for all three of the controls (43000 \pm 7000$)$, even in the absence of any fluorophore, as in the no-DNA condition. These data demonstrate two points: (1) thiolated enzyme strands are not released to a significant extent after chemisorption to Au, and (2) any nonspecific adsorption of substrate strands on the Au surface containing $\mathrm{MCH}$ is minor. The comparable fluorescence intensities from all three negative controls indicate that the reaction buffer used for the $\mathrm{Pb}$ (II)

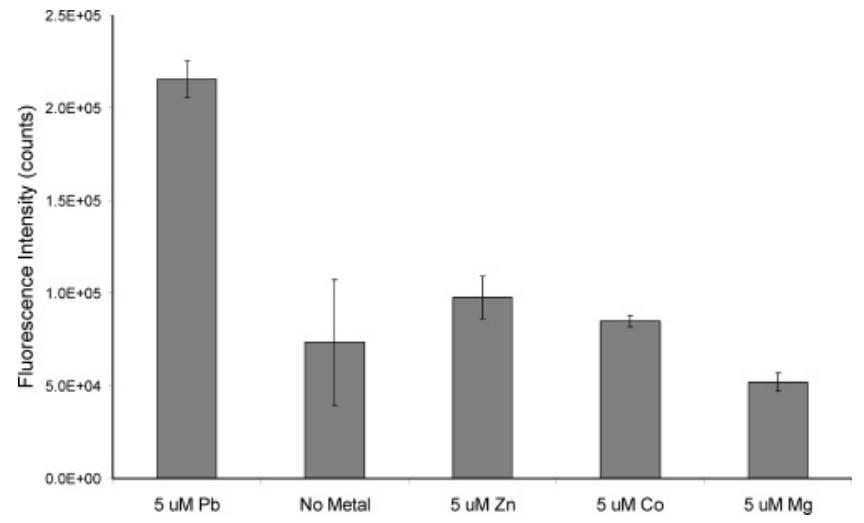

Figure 5. Fluorescence intensities for DNAzyme assembled on $\mathrm{Au}$ surface after reaction with various interfering divalent metal ions. Standard deviation represents measurements on three distinct surfaces.

recognition reaction, not liberation of either fluorescent strand from the Au surface, is responsible for the observed background fluorescence. The relatively high fluorescence intensity 460000 $\pm 30000)$ for the DNAzyme positive control, compared to the negative controls, indicates that the sensor is responding to $\mathrm{Pb}$ (II) as anticipated. In fact, the increase for the DNAzyme is $>700 \%$ upon addition of $10 \mu \mathrm{M} \mathrm{Pb}$ (II), indicating that $\mathrm{Pb}$ (II) specifically cleaves surface-bound DNAzyme, just as it does in solution.

For the $\mathrm{Pb}$ (II)-specific DNAzyme sensor on Au, it was necessary to verify that selectivity is maintained in the immobilized state. An experiment was conducted to compare the activity of the DNAzyme with $\mathrm{Pb}(\mathrm{II})$ to that of its previously identified most strongly interfering divalent metal ions $\mathrm{Zn}$ (II) and $\mathrm{Co}_{\mathrm{O}}$ (II) and the biologically relevant ion, $\mathrm{Mg}$ (II) ${ }^{26}$ Detection was performed as previously described, independently reacting $5 \mu \mathrm{M}$ of each of the above listed metal ions with the surface-bound DNAzyme and additional control samples with no added metal ion. Figure 5 shows the fluorescence intensity of the interfering ions to be within error of the control intensity. The $\mathrm{Pb}$ (II)-reacted samples, however, show $\sim 300 \%$ the intensity observed for the control. This demonstrates that the $\mathrm{Au}$-thiol immobilization has not lowered the specificity of the $\mathrm{Pb}$ (II) DNAzyme.

A critical figure of merit for molecular recognition chemistry to be exploited in a functional sensor is its ability to determine the analyte of interest in a useful concentration range. A calibration curve for $\mathrm{Pb}$ (II) activity on the DNAzyme immobilized sensor is shown in Figure 6. A linear response can be achieved over a wide range, $10 \mu \mathrm{M}>[\mathrm{Pb}$ (II)] $>1 \mathrm{nM}$, though linearity deviates at higher $\mathrm{Pb}$ (II) concentrations. The error associated with these measurements, as characterized by the $\pm \sigma$ error bars on the points in Figure 6, is due partially to variations in the physical dimensions of Au substrates that are linked directly to uncertainties in surface coverage. In addition, the self-assembly of biological molecules, with its inherent dependence on local structure, can also contribute to the statistical variation. ${ }^{47}$

A major advantage of utilizing a surface-immobilized DNAzyme for analyte recognition is the ability to regenerate the surface, so that the DNAzyme can be reused. To test the possibility of regenerating previously cleaved DNAzyme molecules, an experi-

(47) Steel, A. B.; Levicky, R. L.; Herne, T. M.; Tarlov, M. J. Biophys. J. 2000, $79,975-981$. 


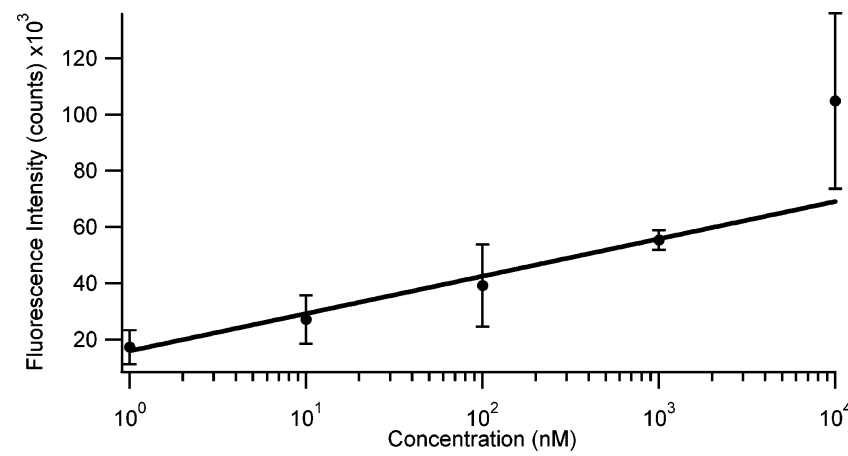

Figure 6. Fluorescence intensities for DNAzyme assembled on $\mathrm{Au}$ surface at various $\mathrm{Pb}$ (II) concentrations. Standard deviation represents three distinct surfaces.

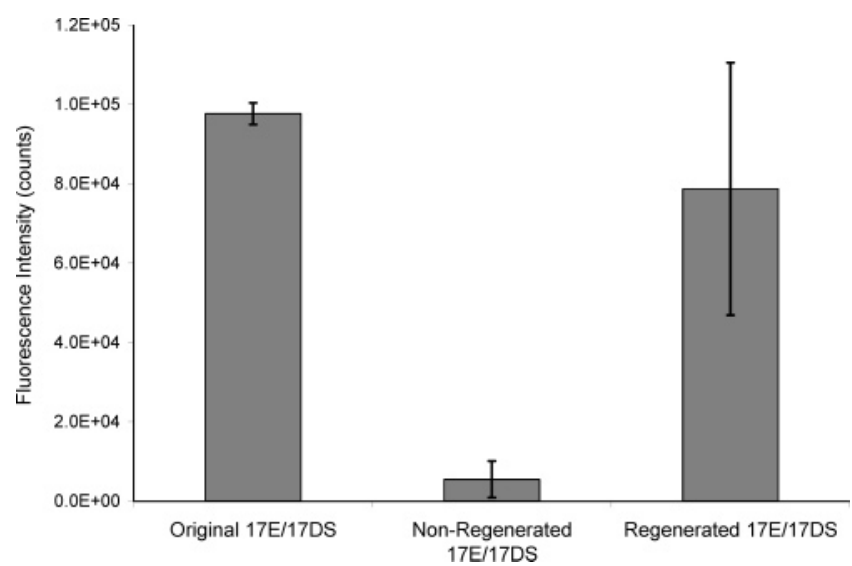

Figure 7. Fluorescence intensities for DNAzyme, a nonregenerated surface, and regenerated surface in the presence of $\mathrm{Pb}$ (II). Error bars represent the standard deviation obtained from replicate measurements on at least two distinct surfaces.

ment was performed in which DNAzyme was initially reacted with $\mathrm{Pb}$ (II). Following the $\mathrm{Pb}$ (II) recognition reaction the surface was soaked in deionized $\mathrm{H}_{2} \mathrm{O}$ for $18 \mathrm{~h}$ to remove the substrate strands (both cleaved and uncleaved). The remaining immobilized enzyme strands were then rehybridized with 17DS-Fl, and the DNAzyme surface was again reacted with $10 \mu \mathrm{M} \mathrm{Pb}$ (II). The regenerated DNAzyme surface elicited a fluorescence intensity $81 \%$ of the original upon exposure to $\mathrm{Pb}(\mathrm{II})$, viz. Figure 7 . In contrast, exposure of nonregenerated, DNAzyme to $\mathrm{Pb}$ (II) produced fluorescence only $6 \%$ of the intensity produced by the original reaction, a value comparable to that produced by the negative controls, cf. Figure 4.

Since the surface-bound DNAzyme can be regenerated, the possibility exists of storing the DNAzyme surfaces for later use or reuse. This is a necessity, if they are to be incorporated as the active elements of microfluidic-based sensor structures for field use. Preliminary results indicate that this is possible. DNAzyme surfaces were completely assembled with mixed monolayers of thiolated enzyme strand and $\mathrm{MCH}$ on $\mathrm{Au}$, followed by hybridization with substrate strand. A portion of the DNAzyme structures were reacted with $\mathrm{Pb}$ (II) immediately, while the remaining structures were stored dry for a period of 1 day followed by reaction with $\mathrm{Pb}$ (II). The stored substrates produced a $\mathrm{Pb}$ (II)induced fluorescence intensity indistinguishable $(0.98 \pm 0.08)$ from that of substrates used immediately after preparation. Unfortunately, significant fluorescence intensity $\left(0.14 I_{\text {control }}\right)$ is also observed in the absence of $\mathrm{Pb}$ (II) as well. The increased background most likely arises from nonspecific dissociation upon drying, loss of orientation of the enzyme strand, and nonspecific cleavage when moisture is not completely removed.

\section{CONCLUSIONS}

As biological experiments test lead toxicity on ever lower concentrations of lead, the acceptable exposure levels have fallen, requiring improved detection limits for $\mathrm{Pb}$ (II) determinations. Not surprisingly, there is a push for robust, sensitive, and selective methods to detect $\mathrm{Pb}$ (II) in situ, especially because of the wellknown detrimental effects to children. Field-useable methods for $\mathrm{Pb}$ determinations must possess the analytical figures of merit possessed by laboratory methods, and be rugged and regenerable, to enable long-time unattended use. Working toward this goal, this work demonstrates the applicability of a molecular beacon approach based on a Au surface-immobilized DNAzyme that is specifically cleaved in the presence of $\mathrm{Pb}(\mathrm{II})$. The cleavage reaction frees a fluorophore-containing fragment, effectively removing it from the vicinal region near a quencher on the complementary strand. Subsequent fluorescence measurements are linear in $\mathrm{Pb}$ (II) concentration in the range $10 \mu \mathrm{M}>[\mathrm{Pb}$ (II)] $>1 \mathrm{nM}$. Additionally, the intact DNAzyme can be regenerated after use for subsequent measurement cycles. The immobilized DNAzyme may also be dried after assembly with little loss of activity indicating that the immobilized system is robust. All these results suggest that the Au surface-based DNAzyme- $\mathrm{Pb}$ recognition event leading to molecular beacon operation is suitable for incorporation into a portable $\mathrm{Pb}$ (II) detection device.

What else is needed for a practical DNAzyme-Pb-based sensor? The selectivity of currently available $\mathrm{Pb}$ detection schemes is relatively high, with a selectivity between 2 and 3 orders of magnitude over other divalent metal ions. ${ }^{26}$ However, this may not be sufficient in some applications. Incorporating the DNAzyme into a microfluidic device offers a convenient package and the ability to include capillary ion analysis on selected analyte bands prior to the $\mathrm{Pb}$ determination for greatly improved selectivity. We expect that the combination of immobilized DNAzyme inside the nanopores of a hybrid nanofluidic/microfluidic device will offer a convenient method of accomplishing this. ${ }^{48-53}$ Although all of the experiments discussed here were performed on planar $\mathrm{Au}$, there is every reason to believe the molecular beacon chemistry can be ported to other Au-coated surfaces, such as the electrolessly deposited $\mathrm{Au}$ on the interior of nanocapillaries, to yield a flowthrough device compatible with a preseparation. Since the ratelimiting step is diffusion to and away from the Au surface, incorporation into a flow-through device is expected to improve

(48) Kuo, T.-C.; Sloan, L. A.; Sweedler, J. V.; Bohn, P. W. Langmuir 2002, 17 , 6298-6303.

(49) Yang, H. C.; Kuo, P. F.; Lin, T. Y.; Chen, Y. F.; Chen, K. H.; Chen, L. C.; Chyi, J.-I. Appl. Phys. Lett. 2000, 76, 3712.

(50) Spencer, M. G.; Flachsbart, B. R.; Yasunaga, T.; Kuo, T.-C.; Sweedler, J. V.; Bohn, P. W.; Shannon, M. A., MicroTotal Analysis Systems 2001, Monterey, CA, Kluwer Academic: New York, 2001; pp 195-196.

(51) Kuo, T. C.; Cannon, D. M.; Chen, Y. N.; Tulock, J. J.; Shannon, M. A. Sweedler, J. V.; Bohn, P. W. Anal. Chem. 2003, 75, 1861-1867.

(52) Kuo, T. C.; Cannon, D. M.; Shannon, M. A.; Bohn, P. W.; Sweedler, J. V. Sens. Actuators, A 2003, 102, 223-233.

(53) Cannon, D. M., Jr.; Kuo, T.-C.; Bohn, P. W.; Sweedler, J. V. Anal. Chem. 2003, 75, 2224-2230. 
reaction times dramatically. Research en route to this goal is ongoing.

\section{ACKNOWLEDGMENT}

This work was supported by the National Science Foundation Science and Technology Center for Advanced Materials for Water Purification, the Strategic Environmental Research and Develop- ment Program, and the Department of Energy through Grant 99ER62797. Juewen Liu is acknowledged for helpful discussions on DNAzyme hybridization.

Received for review May 20, 2004. Accepted October 9, 2004.

AC0401016 